\title{
Characterization of Hybrid Bioactive Glass-polyvinyl Alcohol Scaffolds Containing a PTHrP-derived Pentapeptide as Implants for Tissue Engineering Applications
}

\author{
D.J. Coletta ${ }^{1, \#, *}$ D. Lozano ${ }^{2, \#}$, A.A. Rocha-Oliveira ${ }^{\# 3}$, P. Mortarino ${ }^{1, \#}$, G.E. Bumaguin ${ }^{1}$, E. Vitelli ${ }^{1}$, \\ R. Vena ${ }^{4}$, L. Missana ${ }^{5,6}$, M. V. Jammal ${ }^{5,6}$, S. Portal-Núñez ${ }^{2}$, M. Pereira ${ }^{3}$, P. Esbrit ${ }^{2}$ and S. Feldman ${ }^{1}$
}

${ }^{1}$ Laboratorio de Biología Osteoarticular, Ingeniería Tisular y Terapias Emergentes (LABOATEM), Facultad de Ciencias Médicas de la Universidad Nacional de Rosario, Rosario, Argentina

${ }^{2}$ Laboratorio de Metabolismo Mineral y Óseo, Instituto de Investigación Sanitaria (IIS)-Fundación Jiménez Díaz, and Red Temática de Investigación Cooperativa de Envejecimiento y Fragilidad (RETICEF), Instituto de Salud Carlos III, Madrid, Spain

${ }^{3}$ Laboratorio de Biomateriais, Departamento de Engenharia Metalúrgica e de Materiais, Universidade Federal de Minas Gerais, Belo Horizonte, Brasil

${ }^{4}$ Instituto Biología Rosario (IBR), Universidad Nacional de Rosario, Argentina

${ }^{5}$ Laboratorio de Patología Experimental e Ingeniería de Tejidos. PROIMI-CONICET, Tucumán, Argentina

${ }^{6}$ Laboratorio de Patología Experimental, Diagnóstico e Ingeniería de Tejidos, Facultad de Odontología, Universidad de Tucumán, Tucumán, Argentina

\begin{abstract}
Hybrid foam (BG-PVA) with $50 \%$ Bioactive glass (BG) and $50 \%$ polyvinyl alcohol (PVA) was prepared by sol-gel process to produce scaffolds for bone tissue engineering. The pore structure of hydrated foams was evaluated by 3 D confocal microscopy, confirming $70 \%$ porosity and interconnected macroporous network. In this study, we assessed the putative advantage of coating with osteostatin pentapeptide into BG-PVA hybrid scaffolds to improve their bioactivity. In vitro cell culture experiments were performed using mouse pre-osteoblastic MC3T3-E1 cell line. The exposure to osteostatin loaded-BG-PVA scaffolds increase cell proliferation in contrast with the unloaded scaffolds. An in vivo study was selected to implant BG-PVA scaffolds, non-coated (Group A) or coated (Group B) with osteostatin into non critical bone defect at rabbit femur. Both groups showed new compact bone formation on implant surface, with lamellae disposed around a haversian canal forming osteons-like structure. We observed signs of inflammation around the implanted unloaded scaffold at one month, but resolved at 3 months. This early inflammation did not occur in Group B; supporting the notion that osteostatin may act as anti-inflammatory inhibitor. On the other hand, Group B showed increased bone formation, as depicted by many new trabeculae partly mineralized in the implant regenerating area, incipient at 1 month and more evident at 3 months after implantation. PVA/BG hybrid scaffolds present a porous structure suitable to support osteoblast proliferation and differentiation. Our in vitro and in vivo findings indicate that osteostatin coating improves the osteogenic features of these scaffolds
\end{abstract}

Keywords: Bioactive glass, bone regeneration, femur bone lesion, hybrid matrix, polyvinyl alcohol.

\section{INTRODUCTION}

High rates of fractures worldwide have motivated the development of strategies to promote damaged bone tissue repair. The use of bone allograft materials arose due to the

*Address correspondence to this author at the Laboratorio de Biología Osteoarticular, Ingeniería Tisular y Terapias Emergentes (LABOATEM), Facultad de Ciencias Médicas de la Universidad Nacional de Rosario, Rosario, Argentina; Tel: 5493415837720;

Emails: saryfeldman@yahoo.com.ar; saryfeldman@gmail.com

"ex-aequo. limited amount of autologous bone available for implants. Human bone implants could prevent a putative antigenic host response, although they increase the risk of infection before and after surgery $[1,2]$. A tissue engineering strategy involves the use of a scaffold as a three-dimensional template to guide bone repair. Ideally, this scaffold will give support to cells and/or osteogenic agents to help stimulate the natural bone regenerative mechanisms. These technologies have evolved in the last years towards the development of optimal tissue substitutes based on a better understanding of structure-function relations in normal and 
diseased tissue. Using this approach, smart biomaterials have been developed, which can promote the reestablishment of lost tissue function as a result of trauma [3-6]. An ideal scaffold for bone regeneration must display osteoconductivity and osteoinductivity features, and it would also be able to support load inputs when implanted in bone [7]. Such scaffold would consist of a biomaterial with an inter connected porous network structure and its shape should be adapted to fill a particular defect $[8,9]$.

The development of inorganic-organic composites attempts to create a balance between strength and toughness, in turn improving the characteristics commonly found in the individual components of the composite. These composites can be synthesized through a hybridization route, combining two or more organic and inorganic components [10-15]. Solgel technology allows for the incorporation of different types of polymers within an inorganic silica bulk, thus producing organic-inorganic hybrid materials. The bioactive inorganic and polymer components of these scaffolds should biodegrade over time, allowing bone to remodel naturally, without a toxic response caused by the degradation products $[12,15]$. Also, orgaic-inorganic hybrids has been recognized as a strategy to improve the mechanical behavior of biosactive glass-based materials.

In this regard, bioactive glass (BG)-polymer hybrids are promising materials for biomedical applications because they combine BG bioactivity and the flexibility of polymers. In a previous study, hybrid foams with 50\% BG and 50\% polyvinyl alcohol (PVA) were prepared by the sol-gel process for application as scaffolds in bone tissue engineering. The surfactant-aided foaming process produces interconnected macroporous, and a nanoporous texture is inherent to the sol-gel process. The foams support compressive strengths of $0.60 \mathrm{MPa}$ with a modal interconnect diameter of $250 \mu \mathrm{m}$ between the larger spherical pores (diameter in the range of $100-500 \mu \mathrm{m}, 68 \%$ porosity). These types of foams have structural characteristics that comply with the aforementioned surgeon's criteria. In vitro studies showed that osteoblastic cells maintained their viability in cultures containing these hybrid foams [15].

A suitable approach in bone tissue engineering consists of decorating a biomaterial scaffold with osteogenic agents in order to promote the repair process. In this respect, we recently coated several Si-doped ordered mesoporous ceramics with a parathyroid hormone-related protein (PTHrP)-derived peptide, PTHrP (107-111) (TRSAW, osteostatin) [16-18]. Immobilized osteostatin by covalent binding to the surface of these materials was similarly bioactive as the freely diffusible peptide when tested in osteoblastic cell cultures $[17,18]$. This pentapeptide conferred osteogenic properties to these ceramics when implanted into a cavitary defect in rabbits $[19,20]$. These findings suggest that osteostatin can be a bone regenerating factor.

In the present study, we assessed the putative advantage of coating the osteostatin pentapeptide into BG-PVA hybrid scaffolds for improving their bioactivity. To this aim, we used an in vitro approach in osteoblastic cell cultures and an in vivo model by implanting these scaffolds in a non critical bone defect in rabbits.

\section{MATERIALS AND METHODS}

\section{Hybrid BG-PVA Matrix Synthesis}

The reagents used to synthesize the materials were: tetraethyl orthosilicate (TEOS) (Sigma-Aldrich, Saint Louis, USA), hydrofluoric acid (HF) $80 \%$ hydrolyzed (Merck, Darmstadt, Germany), PVA (Sigma-Aldrich, St. Louis, MO); and surfactant sodium lauryl ether sulfate (Sulfal, Belo Horizonte, Brazil). The hybrids with an inorganic phase composition of $35 \% \mathrm{SiO}_{2}-15 \% \mathrm{CaO}$ and $50 \%$ PVA as organic fraction were prepared by the acid hydrolysis of TEOS followed by the addition of calcium chloride (Vetec, São Paulo, Brazil) and $20 \%$ PVA solution. Twenty seven \% of the surfactant solution and $48 \% \mathrm{HF}$ were then added, mixture was vigorously stirred to form the foam, which was then cast in a container were it gelled, and was dried at $40{ }^{\circ} \mathrm{C}$ in an air circulation oven for one week. Hybrids produced by this method had a highly acidic character conferred by the catalysts added during the process. Thus, an additional neutralization step was necessary to produce biocompatible foams: samples were immersed three times, 30 minutes each, in aqueous-alcoholic calcium acetate solution $(0.5 \mathrm{M})$. After neutralization, the materials were dried again at $40{ }^{\circ} \mathrm{C}$ in an air circulation oven for one week and under high vacuum for $48 \mathrm{~h}[6,15,21]$.

\section{Scanning Electron Microscopy (SEM) and Energy Dispersive X-ray Spectroscopy (EDS)}

SEM images were taken from organic-inorganic hybrids with a Jeol scanning electron microscope equuiped with EDS spectrometer apparatus (JSM 6360V, JEOL/Noran, Japan). SEM photomicrographs were used for the evaluation of hybrid foam microstructure. Prior to SEM examination, samples were coated with a thin gold film by sputtering. Images of secondary electrons (SE) were obtained using an accelerating voltage of $10-15 \mathrm{kV}$. Images were acquired with two different magnifications (100 and 200x).

\section{Confocal Microscopy}

A Nikon eclipse TE2000-E inverted microscope, Declipse C1si scan head, (Nikon Instruments Inc., Melville, New York) was used. Materials were stained with fluorescein and excited at $488 \mathrm{~nm}$ with an argon laser. Fluorescence was detected at $515 \mathrm{~nm}$ using a 35 bandwidth filter. Serial optical sections in the $\mathrm{z}$ axis were captured by laser scanning confocal microscopy with a resolution of 1.25 um at 512x512 pixels, with a Plan Apo 20x objective 0.75 N.A (numerical aperture of the objective). Z-stacks were rebuilt on 3D representation with Nikon C1 software.

\section{Preparation of PVA/BG Scaffolds with Adsorbed Osteostatin}

Hybrid scaffolds 50\% PVA $/ 50 \%$ (\% $\mathrm{m} / \mathrm{m})$ GB BG were loaded with synthetic osteostatin (Bachem, Bubendorf, Switzerland) by soaking them in a solution of each peptide (at $100 \mathrm{nM}$ ) in $1 \mathrm{ml}$ of phosphate-buffered saline, $\mathrm{pH} 7.4$ (PBS) at $4{ }^{\circ} \mathrm{C}$ under stirring for $24 \mathrm{~h}$. Peptide release was 
assessed by either measuring absorbance at $280 \mathrm{~nm}$ or including a radiotracer based on an osteostatin-extended sequence, ${ }^{125} \mathrm{I}\left[\mathrm{Tyr}^{116}\right.$ ]TRSAWBzFSTAAYGLLE $(20,000$ $\mathrm{cpm})$ together with non-radiolabeled osteostatin during loading, as described elsewhere [16, 17]. In the latter case, the released radioactivity into the incubation medium was sequentially monitored for several hours by counting in a $\gamma$ spectrometer.

\section{Cell Culture Studies}

Cell culture experiments were performed using the well characterized mouse pre-osteoblastic MC3T3-E1 cell line $[16,17,22]$. Tested scaffolds were placed into each well of 6- or 24-well plates before cell seeding. Then, MC3T3-E1 cells were plated at a density of 10,000 cells $/ \mathrm{cm}^{2}$ in $2 \mathrm{ml}$ of $\alpha$-minimum essential medium containing $10 \%$ fetal bovine serum, $50 \mu \mathrm{g} / \mathrm{ml}$ ascorbic acid, $10 \mathrm{mM} \mathrm{B-glycerol-2-}$ phosphate and $1 \%$ penicillin-streptomycin at $37^{\circ} \mathrm{C}$ in $5 \%$ $\mathrm{CO}_{2}$, and incubated for different times. Some wells contained no scaffolds as controls. Cell proliferation was determined by addition of Alamar Blue solution (AbD Serotec, Oxford, UK) at $10 \%(\mathrm{v} / \mathrm{v})$ to the cell culture at day 4. Four hours after, 1-ml samples of the cell-conditioned medium were added to 24-well plates, and fluorescence intensity was measured using excitation emission wavelengths of 540 and $620 \mathrm{~nm}$, respectively. In addition, following incubations with the scaffolds for 4 days, cells were washed with PBS, and alkaline phosphatase (ALP) activity was measured in cell extracts obtained with $0.1 \%$ Triton X-100 using p-nitrophenylphosphate as substrate, as described previously $[16,17,22]$. ALP activity was normalized to cell protein content, determined by the BCA (bicinchoninic acid) (Thermo Scientific, Rockford, IL, USA) method with bovine serum albumin as standard. Matrix mineralization was measured by alizarin red staining after cell incubation with the tested materials for 10 days, as described [16, 17, 22]. Stain was dissolved with $10 \%$ cetylpyridinum chloride in $10 \mathrm{mM}$ sodium phosphate, $\mathrm{pH} 7$, and measuring absorbance at $620 \mathrm{~nm}$.

\section{In vivo Bone Hybrid Matrix Implantation With and Without Immobilized Osteostatin in a Non Critical Bone Defect in Rabbit}

Three-month old female New Zealand rabbits $(\mathrm{n}=12)$, kept in individual cages with food and water ad libitum, were used. Animals were randomly subdivided in two groups, and assigned to receive an unloaded (Group A) or osteostatinloaded (Group B) matrix implant ( $n=6$ for each group), as described. Our protocol used a limited number of rabbits and was approved by the Bioethic Committee of our Institutions. Regulations adhere to the well established guidelines for animal care and manipulation to decrease pain and suffering of the animal.

Antibiotic prophylaxis with cefazolin $(50 \mathrm{mg} / \mathrm{kg} / \mathrm{day}$, intramuscularly) was carried out 2 days prior to the surgical procedure, as described [2]. Thereafter, the rabbits were anaesthesized by administering a mixture of ketamine hydrochloride $(35 \mathrm{mg} / \mathrm{kg}) / 2 \%$ xylazine hydrochloride $(18 \mathrm{mg} / \mathrm{kg}) / \quad 1 \%$ acepromazine maleate $(1 \mathrm{mg} / \mathrm{kg})$, subcutaneously, which produced complete relaxation of the animals within 45-60 min (surgical procedure period). Then, a cutaneous longitudinal 4-cm incision was performed in the shaven distal femoral epiphysis. Both, medial and lateral flaps were divided and an opening of a non muscular aponeurotic plane was made until reaching the bone area of interest. The cavitary defect was then created $(6 \mathrm{~mm}$ diameter and $3 \mathrm{~mm}$ deep) by a bit set up to a sterile electrical motor. After washing the bone defect with sterile saline and hemostasis of the lesion with a sterile swab plus gauze, the tested scaffolds, previously rehydrated in the own animal's blood, were implanted and the wounds were sutured. During the period of study (up to three months post-implantation), animals were clinically monitored, body temperature was measured daily during the first week, and then weekly. Biochemical serological parameters (blood cell counts, erythrocyte sedimentation rate, blood glucose, uremia and total serum proteins) were evaluated by standard procedures at days 3 and 11 and at the end of the study. At 1 and 3 months after implantation, 3 rabbits of each group studied removing femora under general anaesthesia, and assigned to histological analysis.

\section{Bone Histology}

Femoral bone samples were submitted to radiographic study using a conventional dental X-ray machine with dental occlusal films (Eastman Kodak Company, Rochester, NY, USA) to determine the implant position to guide the histological procedures. Femoral epiphysis was cut $2 \mathrm{~cm}$ below the metaphysis with a carborundum-disk cutter (Dochem, Shanghai, China) using a dental drill. The implanted area was marked by indian ink. Bone specimens were dehydrated in acetone and embedded in methyl methacrylate. For each specimen, 2-5 series of consecutive sections ( $7-\mu \mathrm{m}$ thick) were cut (at least $150 \mu \mathrm{m}$ apart) with a manual rotative microtome (Micron-Zeiss, Germany), placed on Haupt's adhesive coated slides, and left to dry at $50^{\circ} \mathrm{C}$ for $18 \mathrm{~h}$. The sections were deplastified with ethylene glycol mono ethyl acetate for optimal staining with either toluidine blue ( $\mathrm{pH}$ 3.7) or Goldner Trichrome. Photomicrographs were taken from slides of each specimen by means of a Sony digital camera adapted to an Olympus CH30 microscope. The photos obtained by Soft Pinnacle Studio 9.4 with 116.7X magnification were evaluated by Image Pro Plus analysis system (Media Cybernetics, Silver Spring, MD, USA Version 4.5.0.29 for Windows 1998/NT/2000). New bone formation was quantified and expressed as percentage of total bone (\% BV/TV) in the area surrounding the implant.

\section{Statistical Analysis}

Results are expressed as mean \pm SEM. Statistical evaluation was carried out with nonparametric analysis of variance (Kruskal-Wallis). A value of $p<0.05$ was considered significant.

\section{RESULTS}

The pore structure characterization of the foams used here was evaluated for control purposes. As previously reported $[11,15]$, the tested foams showed pore diameters of $100-300 \mu \mathrm{m}$ as examined by SEM (Fig. 1A and B). It is interesting to investigate the hydrated structure of the 
hybrids because this reproduces the real condition when the foams are implanted. Thus, the pore structure of the hydrated foams was evaluated by 3-D confocal microscopy, which provides information about the bulk structure of the foam. We confirm that these hydrated foams exhibit $70 \%$ porosity (measured by the Archimedes method [11]) and an interconnected network of macroporous (Fig. 2A and B).

In the present study, we assessed the capacity of BGPVA scaffolds to retain osteostatin. It was found that the mean uptake of osteostatin by these scaffolds after $24 \mathrm{~h}$ of loading was $15 \%$, equivalent to $0.2 \mu \mathrm{g}$ peptide/g BG/PVA material. These loaded scaffolds released (as mean \%) $80 \%$ of loaded peptide to the surrounding medium within $1 \mathrm{~h}$ and virtually $100 \%$ at $48 \mathrm{~h}$ (Fig. 3). We next examined the bioactivity conferred by osteostatin to BG-PVA scaffolds in vitro using osteoblastic cell cultures. We found that exposure to osteostatin loaded-BG-PVA scaffolds increased MC3T3E1 cell proliferation over that observed with the unloaded scaffolds. (Fig. 4). Moreover, these peptide-containing scaffolds significantly increased ALP activity and matrix mineralization in these cell cultures (Fig. 5A and $\mathbf{B}$ ).
We also examined here the osteogenic action of osteostatin-coated BG-PVA scaffolds as implants into a non critical bone defect in the epiphysis of the rabbit femur. No clinical or biochemical alterations were detectable in rabbits bearing any of the tested implants with respect to healthy controls. By histological analysis, both experimental groups $\mathrm{A}$ and $\mathrm{B}$ showed new compact bone formation on the implant surface, with lamellae disposed around a haversian canal forming osteons-like structure. Trabecular bone with a reticular or laminar pattern was evident inside the scaffold, at 1 or 3 months, respectively, surrounded by hematopoietic marrow. However, we observed differences in bone repair according to the type of implant (group A or B) within the bone defect.

In group-A rabbits, many inflammatory cells (macrophages and lymphocytes) were detected in the implant/newly formed bone interface at 1 month after implantation. Abundant scattered mineralized nodules were surrounded by inflammatory cells (filled with debris) within the implant at this time period (Fig. 6). However, 3 months after implantation, inflammatory cells were absent and

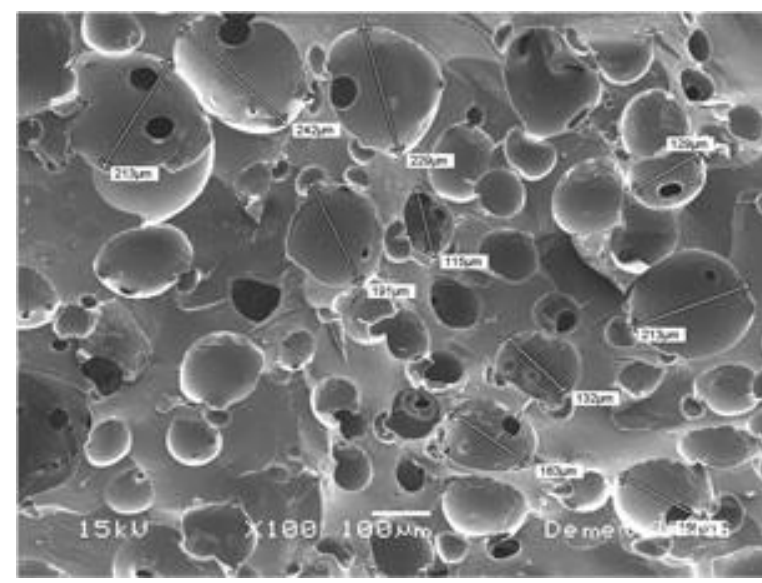

A

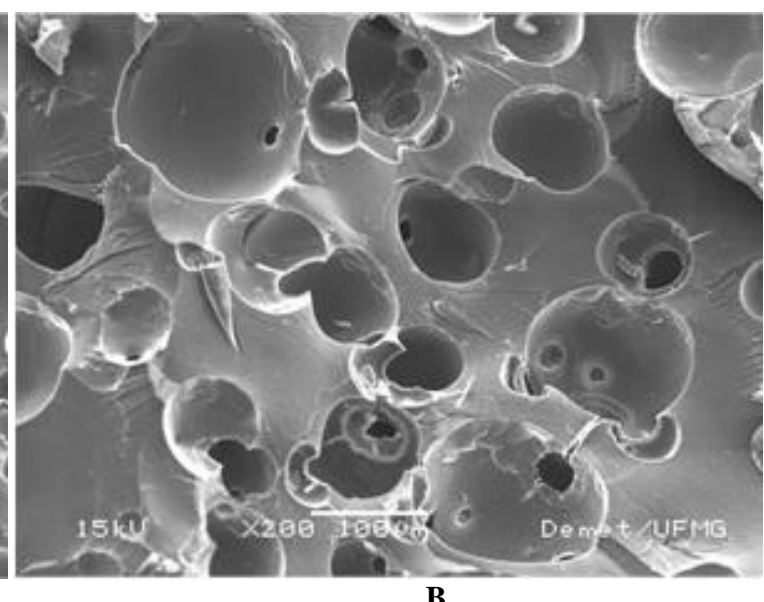

B

Fig. (1). SEM images of hybrid foams with 50\% BG-50\% PVA (A) and respective magnification showing interconnected porous structure (B).

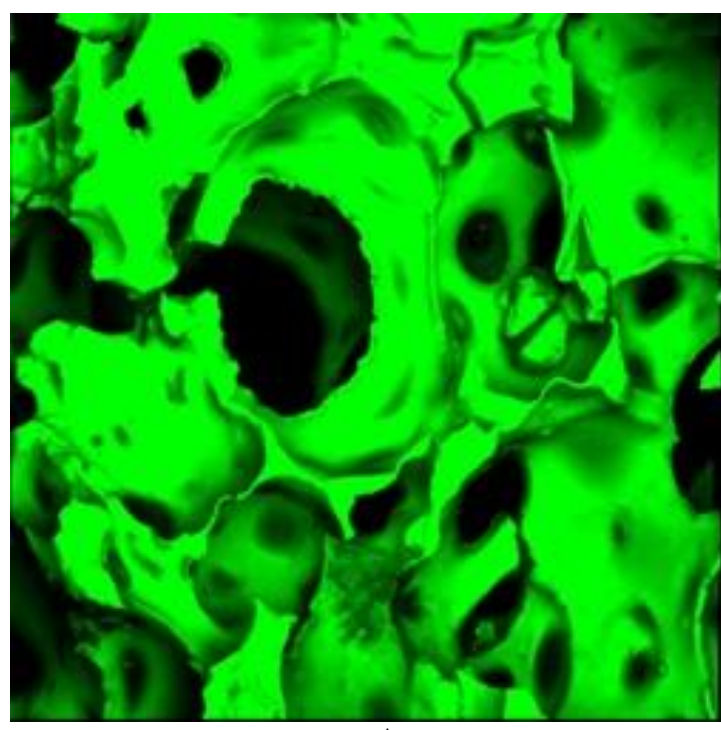

A

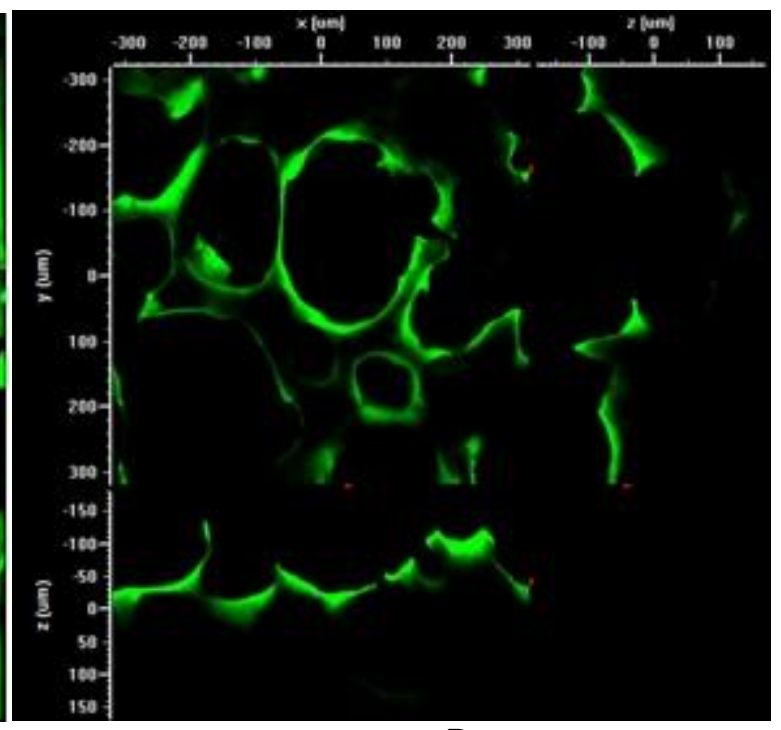

B

Fig. (2). 3-D confocal microscopy images of hybrid foams with 50\% BG-50\% PVA, showing a surface (A) and inner (B) perspective. 


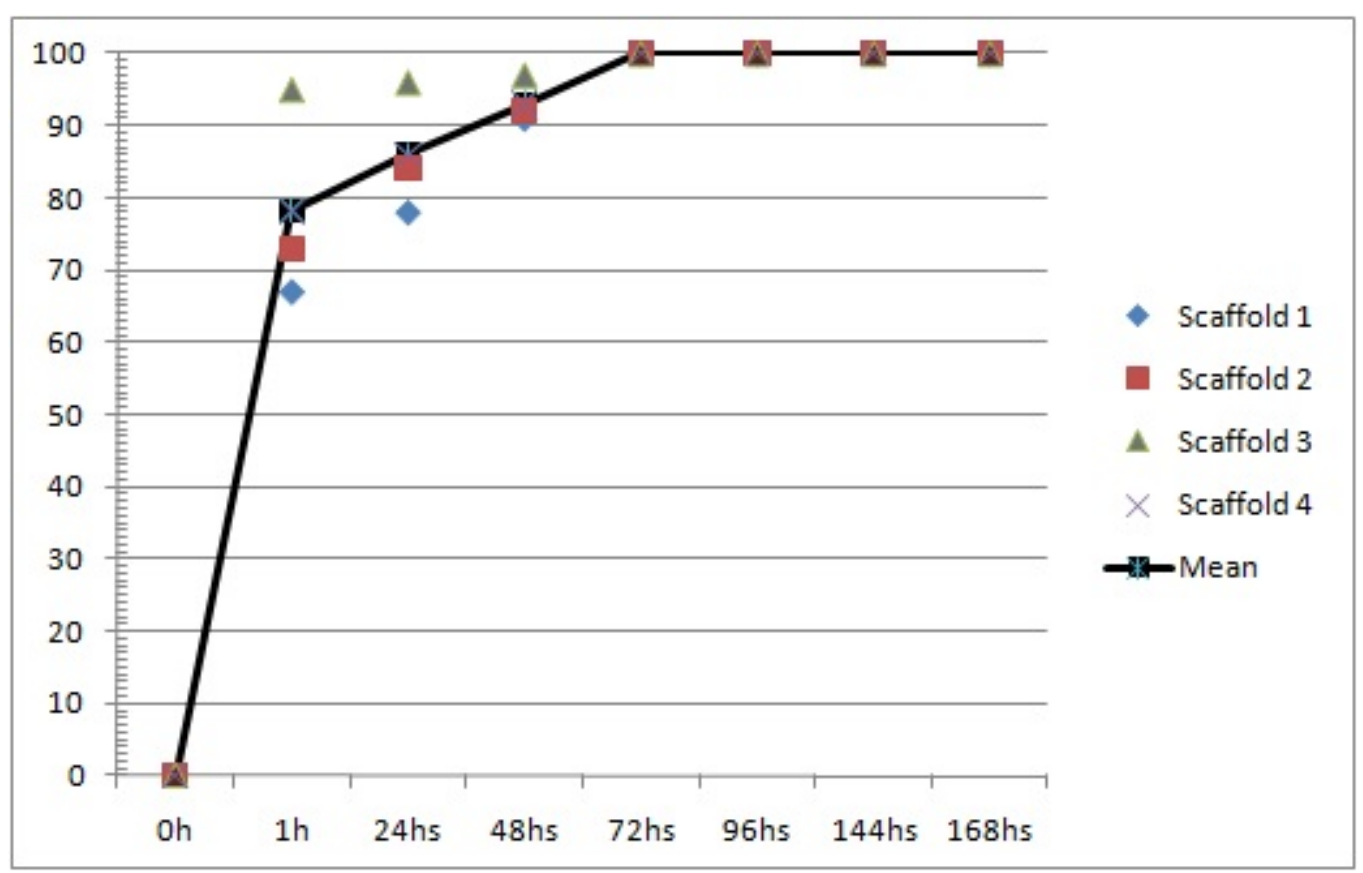

Fig. (3). PTHrP (107-111) release profiles from PVA/BG scaffolds. Points to trace the curve are the means of three independent measurements per time period. The results, expressed as the mean \pm SEM for each scaffold were the following:

For 1h: $78.25 \pm 6.02$; For 24 hs: $7.48 \pm 3.74$; For 48 hs: $2.63 \pm 1.32$; For 72 hs and so on: $100 \pm 0$.

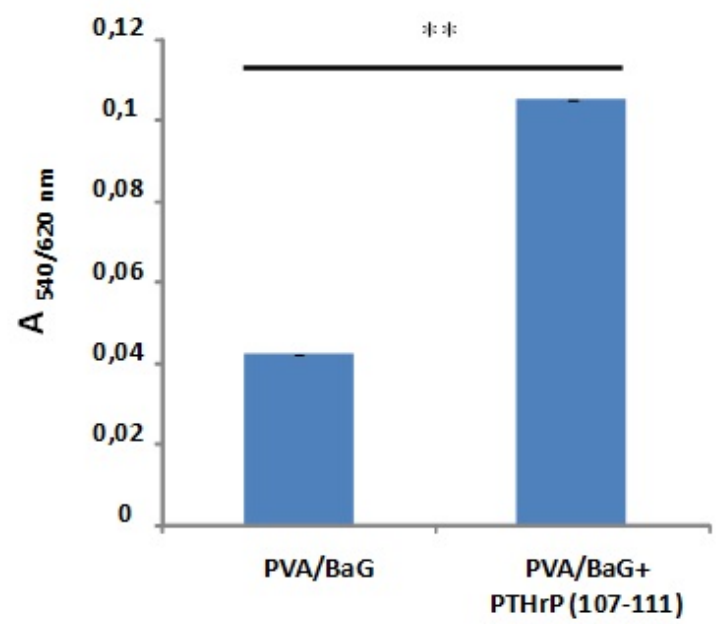

Fig. (4). MCT3T3-E1 cell proliferation (measured by Alamar blue assay) in the presence of PVA/BG loaded or not with osteostatin at day 4 of culture.

Results are mean \pm SEM $(n=4)$. $(0.04266667 \pm 4.6667 \mathrm{E}-0.6$ for PVA/BG and $0.1053333 \pm 0.00037267$ for PVA/BG with PTHrp (107$111)),{ }^{* *} \mathrm{p}<0.01$.

replaced by new cortical bone with osteon-like structures on the implant surface (Fig. 7). Trabecular bone was formed toward the implant core, which was surrounded by osteoid lined with osteoblastic cells, with many debris particles (Fig. 7).

At 1-month after implantation, rabbits from group B showed trabecular bone in the vicinity of cortical bone with osteon-like structures around the peptide-coated scaffold; inside the latter, many thin trabeculae in a reticular pattern and uncompletely mineralized- were observed (Fig. 8). These trabeculae showed a variable osteoid layer with small osteoblastic and lining cells on their surface (Fig. 8). Three months after implantation, an increase of newly formed bone was evident around the peptide-containing scaffold. Meanwhile, many thick trabeculae now invade the scaffold (mainly in its periphery), with abundant lining cells (Fig. 9). Foam debris was present around few trabeculae together with an immature bone marrow. No inflammatory component was present in the bone defect at any time period studied in rabbits with this peptide-loaded implant. Histomorphometric evaluation rendered BV/TV (\%) values of: 54.2 and 59.3 ( $\mathrm{p}<0.5 \%$, by Mann Whitney test) for newly formed (cortical and cancellous) bone in rabbit groups $\mathrm{A}$ and $\mathrm{B}$, respectively, at 3 months after implantation. 


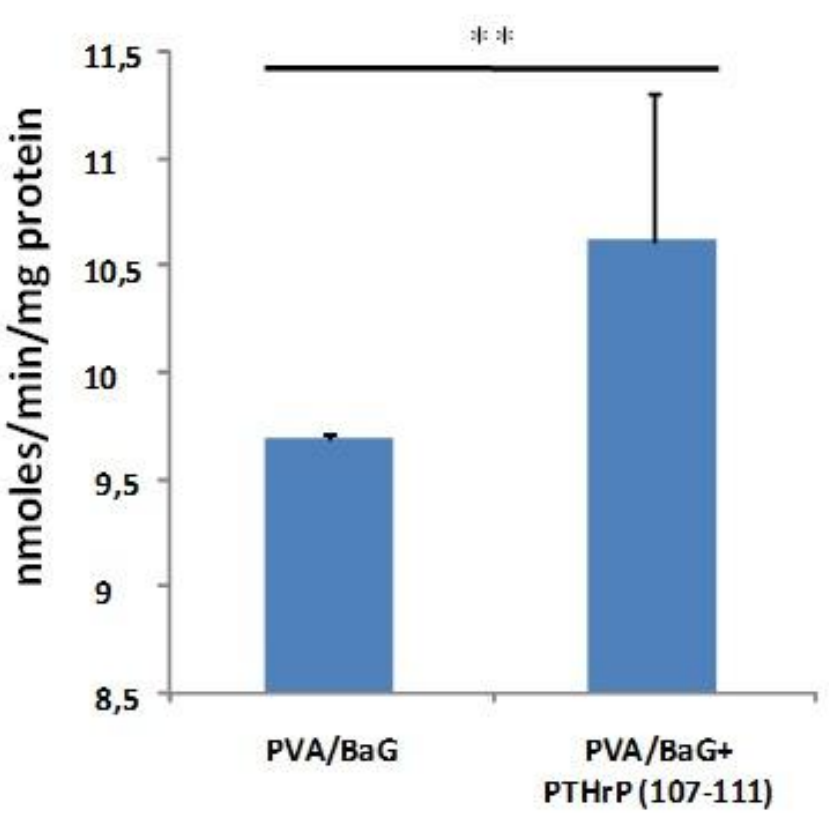

A

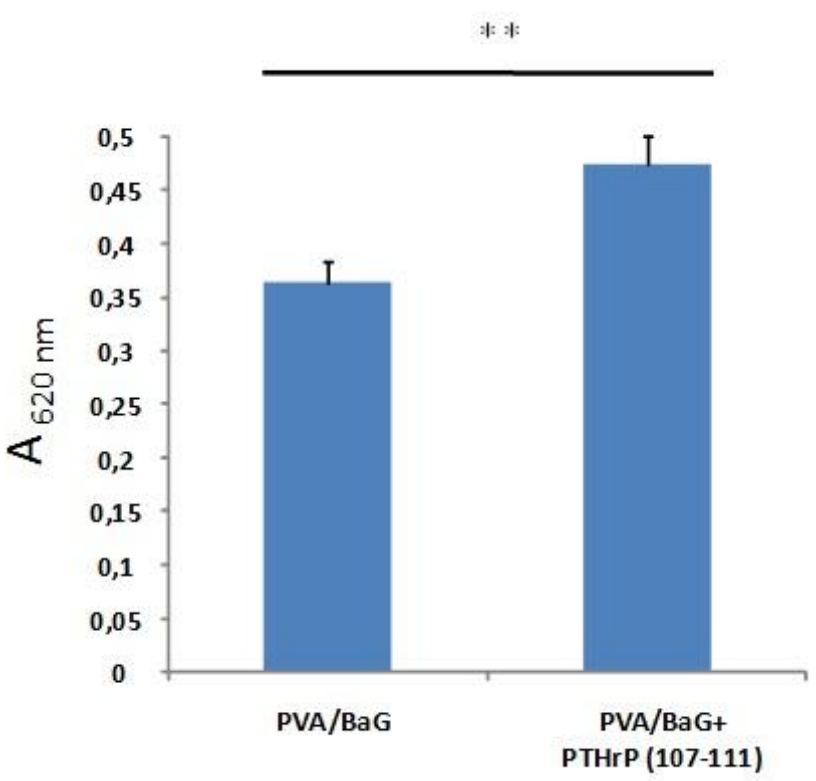

B

Fig. (5). (A) ALP activity in the presence of PVA/BG loaded or not with osteostatin in MC3T3-E1 cells at day 4 of culture. (B) Mineralization in the presence or absence of PVA/BG loaded or not with osteostatin at day 10 of MC3T3-E1 cell culture. Results are mean $\pm \operatorname{SEM}(\mathrm{n}=3) . * * \mathrm{p}<0.01$.

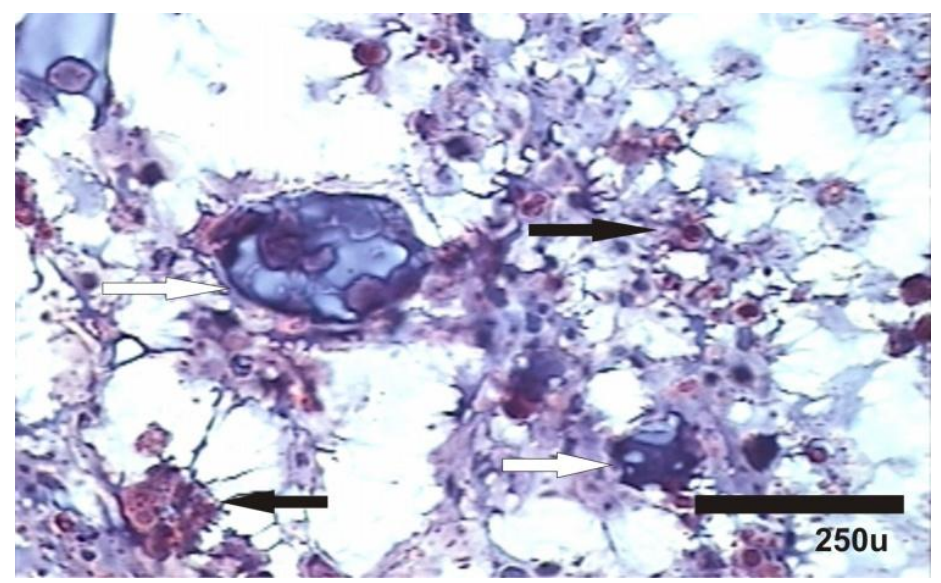

Fig. (6). Representative photomicrograph of a bone section embedded in methyl methacrylate and stained with Goldner's, corresponding to a non-critical defect with peptide-unloaded scaffold at 1 month after implantation in the epiphysis of the distal rabbit femur. Black arrows denote inflammatory cells in the matrix surrounding the implant particles. Mineralized nodules (white arrows) were also present. Magnification, 700x.

\section{DISCUSSION}

The present findings further confirm the validity of the sol-gel technique for producing hybrid scaffold foams with macroporous structure as implants for bone tissue engineering applications $[14,15,21]$.

The BG-PVA scaffolds presented mechanical properties that are suitable for load bearing applications and for supporting 3-D cell growth in bone tissue engineering [1, 2]. The hybrids present resistance features that make them suitable for flexible manipulation to be used as implants to adapt to and fill bone defects $[6,15,21]$. Recent in vitro and in vivo reports using these hybrid scaffolds showed that osteoblasts maintain their viability in the presence of this type of material [15]. These scaffolds also allow mesenchymal cells to grow in 3D cultures [21].

The in vitro and in vivo results obtained in this study further extend previous findings in other experimental systems [16-20, 22], and confirm the ability of osteostatin to confer osteogenic properties to materials of interest for tissue engineering applications. Osteostatin uptake by these BGPVA scaffolds was found to be poorer and its release to the medium was faster than that observed by other previously tested bioceramics $[16,17]$, supporting its efficacy even at very low doses delivered to the bone defect in vivo. 


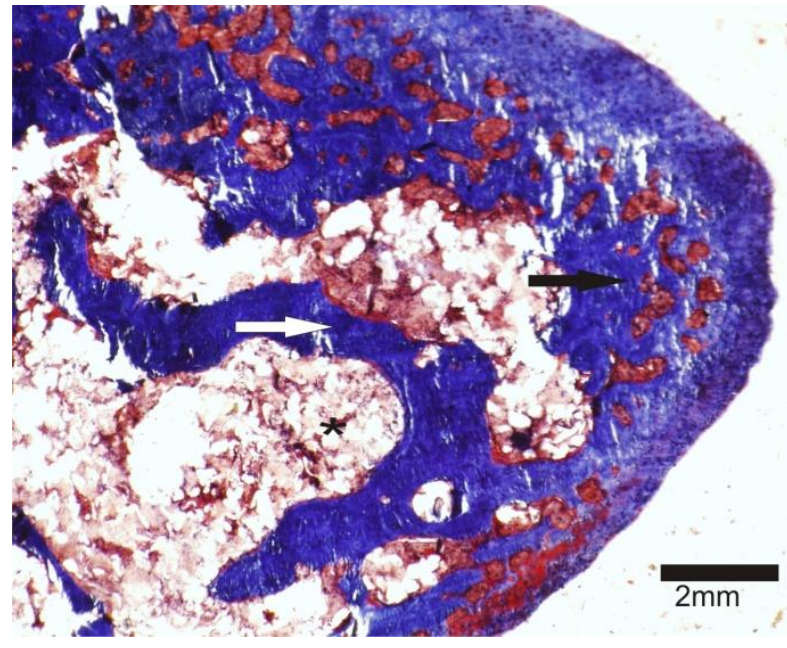

Fig. (7). Representative photomicrographs of methyl methacrylateembedded bone sections stained with Goldner's, corresponding to a non-critical defect with peptide-unloaded scaffold at 3 months after implantation in the epiphysis of the distal rabbit femur. Black arrow indicates cortical bone with Haversian's system in the vicinity of the implant. Trabecular bone -of laminar type- was covered by osteoid (white arrow). Immature haematopoietic marrow and material debris (asterisk) were also observed. Magnification 40x (A); magnification, 63x (B).

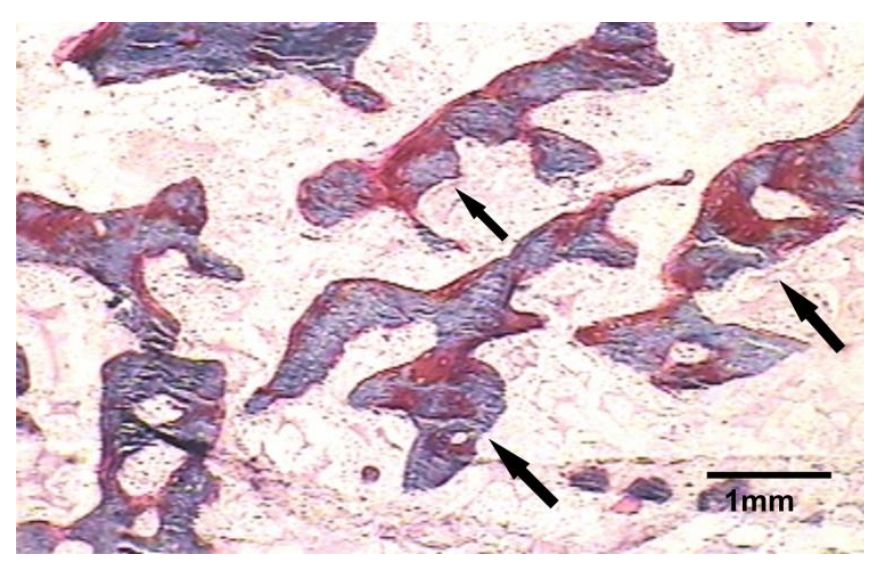

Fig. (8). Representative photomicrograph of a bone section embedded in methyl methacrylate and stained with Goldner's, corresponding to a non-critical defect with osteostatin-loaded scaffold at 1 month after implantation in the epiphysis of the distal rabbit femur. Black arrows indicate abundant new cortical bone in the area around the implant. Many reticular mineralized (blue) and not mineralized (red) bone trabeculae were observed in this area. Magnification 117x.

In our in vivo experimental model, we observed signs of inflammation around the implanted unloaded scaffold at one month, but this was resolved at 3 months. This early inflammation did not occur in the case of the peptide-loaded implant, supporting the notion that osteostatin may act as anti-inflammatory inhibitor as previously suggested [20]. On the other hand, the latter type of implant showed an increased bone forming activity, as depicted by many new trabeculae that were partly mineralized in the regenerating

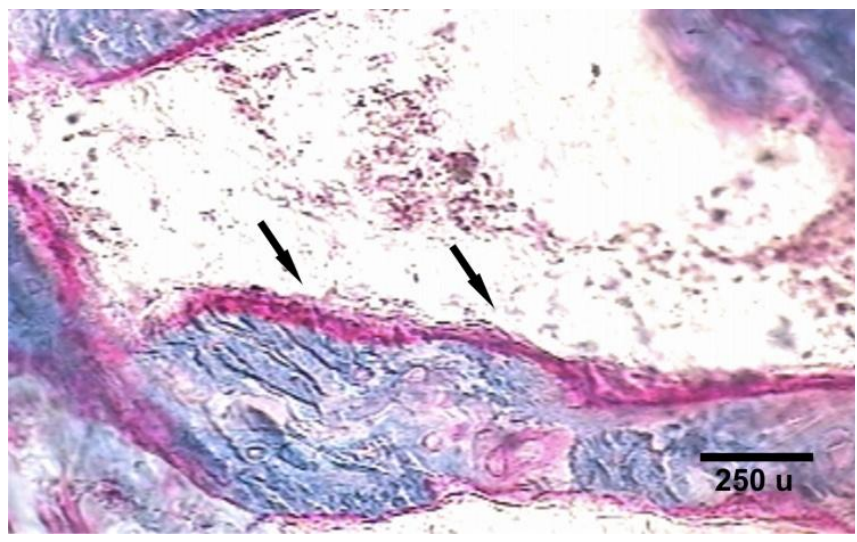

Fig. (9). Representative photomicrograph of a bone section embedded in methyl methacrylate and stained with Goldner's, corresponding to a non-critical defect with osteostatin-loaded scaffold at 3 months after implantation in the epiphysis of the distal rabbit femur. At high magnification (467x), many new mineralized (blue) and not mineralized (red) trabeculae were observed, covered with osteoid and lining cells (black arrows).

area around the implant, beginning at 1 month and more evident at 3 months after implantation.

In summary, PVA/BG hybrid scaffolds present a porous structure suitable to support osteoblast proliferation and differentiation. Our in vitro and in vivo findings indicate that osteostatin coating improves the osteogenic features of these scaffolds. Further studies are warranted to assess the usefulness of these biomaterials in tissue engineering strategies in vivo to promote bone regeneration.

\section{CONFLICT OF INTEREST}

The authors confirm that this article content has no conflicts of interest.

\section{ACKNOWLEDGEMENTS}

This work has been supported by grants from Consejo Nacional de Investigaciones Científicas y Técnicas (CONICET), Argentina, Comunidad Autónoma de Madrid (S-2009/MAT/1472), Instituto de Salud Carlos III (RD06/0013/1002 \& RD/12/0043/0008), Spain, and Conselho Nacional de Desenvolvimento Científico e Tecnológico-CNPq (CIAM 590058/2010-0), Brazil.

We are indebted to Dr. Ricardo Battaglino, Department of Cytokine Biology, The Forsyth Institute, Boston, Massachusetts, USA and to Dr. Oscar Bottasso, Institute of Immunology, School of Medicine, National University of Rosario, for critical reading of the manuscript, and David A. Gatti fron School of Medicine, National University of Rosario, for assistance in computational aspects

\section{PATIENTS CONSENT}

Informed Consent was given to the Author by the patients in respect of the clinical trials conducted. 


\section{REFERENCES}

[1] D. L. Muscolo, A. Ayerza, E. Calabrese, A. A. Redal, and E. Santini Araujo. "Human leucocyte antigen matching, radiographic score and histologic findings in massive frozen bone allografts". Clin. Orthop., vol. 326, pp. 115-126, May 1996.

[2] L. Kremenetzky and S. Feldman Aplicación de aloinjerto óseo como cemento biológico. Rev. Asoc. Argent. Ortop. y Traumatol., vol. 71, pp. 61-66, March 2006.

[3] J. A. Putnam and S. Radin"In Vivo Tissue Response to a reabsorbable silica xerogels as controlled-release materials". Biomaterials, vol. 26, pp. 1043 -1052, March 2005.

[4] D. W. Humacher. "Scaffold design and fabrication technologies for engineering tissues--state of the art and future perspectives". $J$. Biomater. Sci. Polymer., Edition, vol. 12, no.1pp.107-124, DOI: 10.1163/156856201744489, Jan 2001

[5] D. P. Goy, E. Gorosito, S. Costa, P Mortarino, N. Acosta Pedemonte, J. Toledo, H. S. Mansurb, M. M. Pereira, R. Battaglino and S. Feldman. " Hybrid Matrix Grafts to Favor Tissue Regeneration in Rabbit Femur Bone Lesions". Open Biomed. Eng. J., vol. 6, pp. 85-91, Jul. 2012.

[6] A. A. R. de Oliveira, V. Ciminelli, M. S. S. Dantas, H. S. Mansur, and M. M. Pereira. "Acid Character Control of Bioactive Glass/Polyvinyl Alcohol Hybrid Foams Produced by Sol-Gel". $J$. Sol-Gel Sci. Technol., vol. 47, no. 3, pp. 335-346, DOI: 10.1007/s10971-008-1777-1, Sept 2008.

[7] J. R. Jones. "Review of bioactive glass: From Hench to hybrids". Acta Biomater., vol. 9, pp. 4457-4486, DOI: 10.1016/j.actbio.2012.08.023, Jan 2013.

[8] G. Cointry, R. Capozza, S. Feldman, P. Reina, I. Grappiolo, S. E. Ferretti, P. Mortarino, M. Chiappe, and J. L. Ferretti. "Los huesos son estructuras genéticas, metabólicas, biomecánicas, o todo a la vez?". Actual. Osteol., vol. 5, no. 3, pp. 185-195, March 2009. Available from http://www.aaomm.org.ar/Actualizaciones.htm, (Accessed March 2009)

[9] M. M. Pereira, J. R. Jones, and L. L. Hench. "Bioactive Glass and Hybrid Scaffolds Prepared by the Sol-Gel Method for Bone Tissue Engineering". Adv. Appl. Ceram, vol. 104, no. 1, pp. 35-42, Feb 2005.

[10] M. M. Pereira, J. R. Jones, R. L. Orefice, and L. L. Henc., "Preparation of Bioactive Glass-Polyvinyl Alcohol Hybrid Foams by the Sol-Gel Method". J. Mater. Sci. Mater. Med., vol. 16, no. 11, pp. 1045-1050, Nov. 2005.

[11] Oliveira, H. S. Mansur, and M. M. Pereira. "Acid Character Control of Bioactive Glass/Polyvinyl Alcohol Hybrid Foams Produced by Sol-Gel". J. Sol-Gel Sci. Technol., vol. 47, pp. 335346, Sept 2008.
E. A. Corti, S. D'Antone, and R. Solaro. "Biodegradation of poly (vinyl alcohol) based materials". Prog. Polym. Sci., vol. 28 no. 6 , pp. 963-1014, June 2003.

[13] D. W. Hutmacher. "Scaffolds in tissue engineering bone and cartilage". Biomaterials vol. 21, no.24 pp 2529-2543, Dec. 2000 .

[14] J. Drury, and D. J. Mooney. "Hydrogels for tissue engineering: scaffold design variables and applications". Biomaterials, vol. 24 no. 24 , pp. $4337-4351$, Nov. 2003

[15] A. A. R. de Oliveira, V, Gomide, M. F. Leite, H. S. Mansur, and M. M. Pereira. "Effect of polyvinyl alcohol content and after synthesis neutralization on structure, mechanical properties and cytotoxicity of sol-gel derived hybrid foams". Mater Res., vol. 12, no. 2, pp. 1-10, June 2009.

[16] D. Lozano, M. Manzano, J. C. Doadrio, A. J. Salinas, M. ValletRegí, E. Gómez-Barrena and P. Esbrit . "Osteostatin-loaded bioceramics stimulate osteoblastic growth and differentiation". Acta Biomater., vol. 6, no.3, pp. 797-803, Aug 2010.

[17] M. Manzano , D. Lozano , D. Arcos , S. Portal-Núñez , C. L. Orden, P. Esbrit, and M. Vallet-Regí. "Comparison of the osteoblastic activity conferred on Si-doped hydroxyapatite scaffolds by different osteostatin coatings". Acta Biomater., vol. 7, no. 10 , pp. 3555-62, June 2011.

[18] A. J. Salinas, P. Esbrit, and M. Vallet-Regí. " A tissue engineering approach based on the use of bioceramics for bone repair". Biomater. Sci., vol. 1, pp. 40-51, Jul 2013.

[19] C. G. D. Trejo Lozano, M. Manzano, J. C. Doadrio, A. J. Salinas, S. Dapía, E. Gómez-Barrena, M. Vallet-Regí, N. GarcíaHonduvilla, J. Buján and P. Esbrit. "The osteoinductive properties of mesoporous silicate coated with osteostatin in a rabbit femur cavity defect model". Biomaterials, vol. 31, no. 33, pp. 8564-73, Aug 2010.

[20] D. Lozano, C.G. Trejo, E, Gómez-Barrena, M. Manzano, J.C Doadrio, A.J. Salinas, M. Vallet-Regí, N. García-Honduvilla, P. Esbrit and J. Buján. "Osteostatin-loaded onto mesoporous ceramics improves the early phase of bone regeneration in a rabbit osteopenia model" . Acta Biomater., vol. 8, pp. 2317-2323, Jul 2012.

[21] V.S. Gomide, A . Zonari, N.M. Ocarino , A.M. Goes , R. Serakides , and M.M. Pereira . "In vitro and in vivo osteogenic potential of bioactive glass-PVA hybrid scaffolds colonized by mesenchymal stem cells". Biomed. Mater., vol. 7, no. 1, doi: 10.1088/17486041/7/1/015004, Jan 2012.

[22] D. Lozano, M.J. Feito, S. Portal-Núñez, R.M. Lozano, M.C Matesanz, M.C. Serrano, M. Vallet-Regí, M.T . Portolés, and P. Esbrit. "Osteostatin improves the osteogenic activity of fibroblast growth factor-2 immobilized in Si-doped hydroxyapatite in osteoblastic cells". Acta Biomater., vol. 8, no.7, pp. 2770-2777, Apr 2012.

This is an open access article licensed under the terms of the Creative Commons Attribution Non-Commercial License (http://creativecommons.org/licenses/by-nc/3.0/) which permits unrestricted, non-commercial use, distribution and reproduction in any medium, provided the work is properly cited. 